\title{
Design and Development of Automation Production Control System for Production Line
}

\author{
Liu Yongqiu, Zhu Jijin \\ Guangdong University of Science \& Technology, No.99 Xihu Road, Dongguan, Guangdong, \\ 523083, China
}

Keywords: Automation production control system, Software forewarning controlling, Frozen food

\begin{abstract}
The range of operating temperature for production line of frozen food is generally from $-80^{\circ} \mathrm{C}$ to $20^{\circ} \mathrm{C}$, which causes difficulties for food production and food hygiene supervision. The research develops an automation production control system controlled by computer. Experiments show that the system can complete the production control functions of production line of frozen food such as: system regulation, mechanical condition monitoring, health warning and temperature controlling under low temperature, so it promotes the production efficiency of food enterprises and effectively reduces labor costs, and can record and analyze production parameters of various frozen food in processing to provide new approach for the establishment of computer monitoring and optimal parameters of frozen food production lines.
\end{abstract}

\section{Introduction}

With the improvement of modern people's living standard, the demand for all kinds of food is becoming bigger and bigger [1]. According to requirements and needs of market's real-time orders, food production enterprises shall timely adjust and rationally arrange producing food types of all food production lines of enterprises and change food recipes of production lines and processing craft parameters in time so as the make it adapt to food production requirements of next order [2]. Food industry is facing increasingly severe global competition, so it has a strong demand for automation[3]. These requirements mainly reflect in following aspects:

(1) Automation of food factory can lower labor intensity, reduce loss and produce in mass efficiently, thus, product costs can be brought down. Generally speaking, the implementation of automation can cut down the number of equipment of the factory and lessen the artificial and maintenance cost in the meanwhile. Automation system has the accuracy and repeatability that human beings are incomparable and by fine adjustment, it can quickly reach the best operating condition[4]. Therefore, automation has the characteristics of high efficiency and low cost and also greatly improves the production capacity;

(2) Modern quality control methods such as statistical quality control (SQC) and statistical process control(SPC) provide powerful guarantees for product quality[5]. At the same time, factory automation is also good for the implementation of total quality control (TQC);

(3) Data storage for computer-controlled system is easy and actually, the capacity is infinite [6]. The system can store huge amounts of technologies and product information and also can form complete operational report and inventory report. Quality data among product batches shall be used for quality analysis to help technical staffs do process improvement and development. Based on the information, operators may make reports, adjust process parameters, change system settings and run process tests etc. According to reporting materials, online measurement system of a frozen Pizza 
production line can automatically calculate out the average weight, weight range, standard deviation and confidence interval of products[7].

(4) Demands in food hygiene law is becoming stricter and stricter and one of them is to reduce the participation and intervention of people in production process as much as possible for it can be realized by mechanization and automation, in addition, unmanned factory may come true[8]. Modern controllers are more compact and easier to be cleaned and automatic cleaning and sterilization equipment provide a reliable sanitary guarantee.

Frozen food processing is an important aspect in the food industry. Nowadays, people also put forward higher requirements on the quality of frozen food. Simultaneously, because of expansion of production scale of frozen food enterprises, increase in product varieties, constant changing of market demands as well as strict requirements of domestic and foreign large-scale supermarket groups on quality stability of frozen food, higher automation control requirements on frozen lines are put forward by people. For example, as for different quick frozen food, the parameters for freezing time, freezing temperature, freezing speed, refrigerating capacity and cooling curve in frozen production are disparate[9]. In order to adapt to production requirements of various types, fast pace, low energy consumption and easy management, freezing production process must be done a completer automation measurement and control.

The paper develops an automatic production monitoring system that is based on the local area network, adopts the computer measurement and control technology in embedding type and automatically collect low temperatures, voltages and currents as well as process defaults of screw refrigerating units. The system is facilitated with the functions of data processing, recording alarming and program controlling, so it can record and analyze production parameters of various frozen food in processing to provide new approach for the establishment of computer monitoring and optimal parameters of frozen food production lines.

\section{Materials and methods}

Computer monitoring and controlling system for food frozen production lines is the foundation of computer system in quick frozen food enterprises that is composed by three layers: field measurement and control layer, production and management layer and remote service layer.

Field control layer. It is composed by embedded computer, intelligent input and output devices, sensor, actuator, expert algorithm and warning software. It can display cryogenic temperature, technological parameter and state of process and is facilitated with automatic warning function.

Production and management layer. It includes commercial computer or industrial control computer, network communication, printer, monitoring software for frozen food's production systems and expert system software etc. and is equipped with optimization functions of expert system and food's frozen production system.

Remote service layer. It consists of remote communication Internet or telephone network connector, headquarter server, remote data communication, remote diagnosis, analysis software etc. and possesses the functions of remote viewing and analysis of historical data. The field layer of hardware system in computer monitoring and controlling system for food frozen production lines is the application of "computer forewarning system for food production lines". The system is constituted by embedded integration industrial computer, embedded industrial microcontroller, intelligent input and output module, variable-frequency governor, high accuracy sensor and actuator, mainly completes detection and measurement and control functions on the basic data of frozen food production lines and is provided with RS-485 and other communication protocol interfaces[9]. 
Overall structure of computer monitoring and controlling system for food frozen production lines can refer to figure 1.

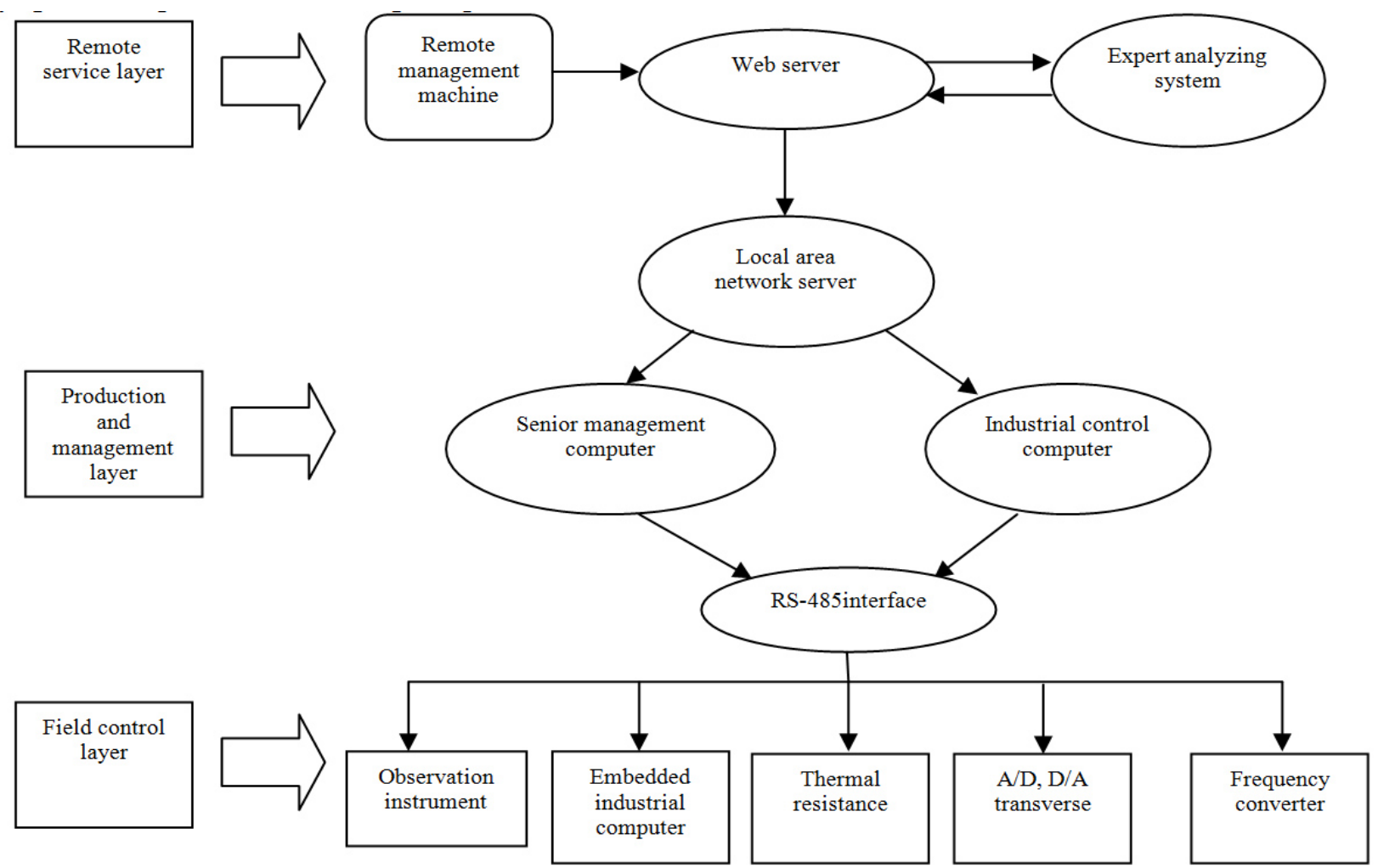

Figure 1 Overall structure of computer monitoring and controlling system for food frozen production lines

Functioning principles and methods. Inner installation of spiral freezer units includes integrated temperature complex sensor, fault detection sensor, electric current transducer and chain plate speed sensor etc. The collected data shall be firstly transmitted to front anti-interference processing module to complete data preprocessing and program stop-start controlling by field embedded microcontroller controller and then it will be passes to embedded integration industrial computer to do whole state processing on data, equipment running status recording and data normalization, finally, it will be provided to site operation personnel by color LCD. Plant-level management personnel can inquire historical recording data by local area network browser. Software structure of computer monitoring and controlling system for food frozen production lines can refer to figure 2 .

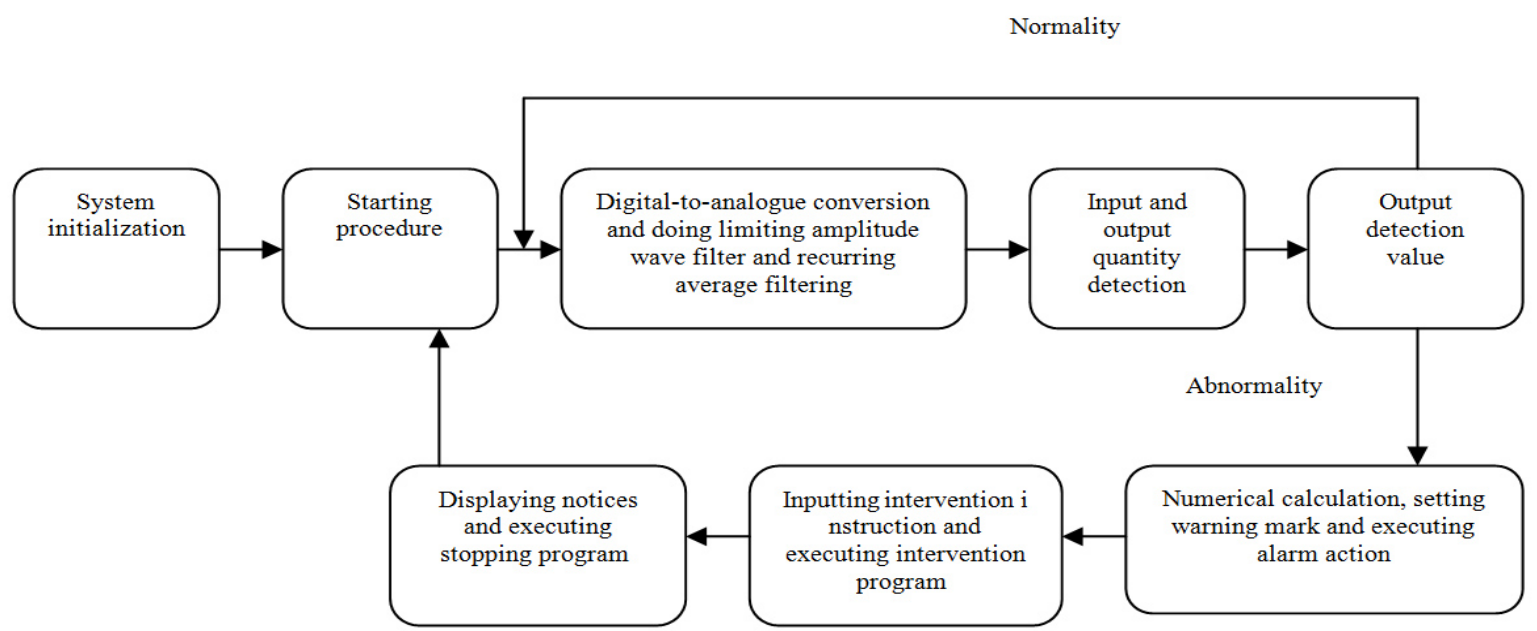

Figure 2 Flow diagram for software data on computer monitoring and controlling system for food frozen production 


\section{Results and discussion}

Main production equipment for food quick freezing is quick-freezing freezer whose internal working temperature range is generally from $-80^{\circ} \mathrm{C}$ to $-20^{\circ} \mathrm{C}$. For its complete close structure, the adjustment, maintenance and management on it is a arduous and difficult systematic working. Because of the very low temperature, technical staffs can only stay in the subzero storage for 3 min to $5 \mathrm{~min}$, in addition, due to the requirements of low temperature, constant temperature and food sanitation safety, application of perennial lighting is not accessible and photographic equipment cannot be installed. Therefore, industrial computer technology must be applied to complete the automatic check on quick-frozen production process condition and data and do recording, analysis and neatening on a mass of data, which shall provide material and guidance for the operation, maintenance and equipment maintenance of refrigeration system to make up the current situation that professional and technical personnel in domestic quick frozen food enterprises are in severe shortage. By experiments, the ultimate finished functions of computer monitoring system function are as following:

(1) It can automatically record the low working temperature of freezing process, speed of operation curve in food keyboard, out-of-limit alarming time of tension degree and also can log the species and names of five detectable technology troubles as well as the out-of-limit value, time and type of alarm of monitored data in automation. It possesses fault remembrance function that offers technical data support for scientific management and equipment maintenance.

(2) It is facilitated with the quite complete manual/automatic control function and under automatic operating state, it can finish the operations of starting and stopping of normal procedure/defrost downtime, door heating and automatic starting or stopping of lighting etc.

(3) It may automatically detect the running current or voltage and starting-stopping state of each main motor.

(4) It shall automatically detect the tension degree of food keyboard and set up too high/too low warning limits for tension degree and once exceeding the limitation, it will be in auto-alarm.

(5) It can automatically detect the operation line speed of food keyboard and also calculate the production rate and production quantity of spiral freezer.

(6) It shall automatically monitor the low working temperature of food freezing process and the detection range is from $-80^{\circ} \mathrm{C}$ to $40^{\circ} \mathrm{C}(10$ to 20 monitoring sites can be set up.)

(7)Color LCD may dynamically display running information and alarm measuring information of main technologies in the production process of frozen food, which enables the production operation manager to have a clear understanding on production operation situation to reduce blind operation.

\section{Conclusion}

The computer monitoring and controlling system for food frozen production lines completed in the project is just the foundation of computer system of food frozen production enterprises. According to plan, computer data optimization and management expert system of frozen food production lines shall be set up; computer analysis and management expert software of frozen production data will be developed; refrigeration expert knowledge and technology based on data developing technology may be explored so as to promote the technological level of domestic food frozen industry, enhance the scientific and technological content of food frozen equipment, elevate the product grade and service taste of frozen production equipment as well as the overall level of frozen food and equipment and strengthen enterprises’ competitiveness. 


\section{Acknowledgement}

This paper is funded by Project of "Search On the building Platform of School-Enterprise cooperation based on Industrial Robots”, 2015 school level“ innovation and school powered project”, NO (GKY-2015CQYB-1).

\section{References}

[1] Li, J., Lu, H., Zhu, J., Wang, Y., \& Li, X. (2009). Aquatic products processing industry in China: Challenges and outlook. Trends in food science \& technology, 20(2), 73-77.

[2] Tsola, E., Drosinos, E. H., \& Zoiopoulos, P. (2008). Impact of poultry slaughter house modernisation and updating of food safety management systems on the microbiological quality and safety of products. Food Control,19(4), 423-431.

[3] Awad, T. S., Moharram, H. A., Shaltout, O. E., Asker, D., \& Youssef, M. M. (2012). Applications of ultrasound in analysis, processing and quality control of food: A review. Food Research International, 48(2), 410-427.

[4] Chen, Y., \& Xu, J. J. (2015). The Brittleness Analysis Based on the Rule of Brittleness being Motivated and its Application. Journal of Applied Science and Engineering Innovation Vol, 2(3), 67-70.

[5] Sun, D. W. (Ed.). (2011). Handbook of frozen food processing and packaging. CRC Press.

Pei Tang and Shanhong Zhu, 2015. Research on Food Safety Guarantee System Based on AHP. Advance Journal of Food Science and Technology, 7(2): 110-112.

[6] Rodgers, S. (2008). Technological innovation supporting different food production philosophies in the food service sectors. International Journal of Contemporary Hospitality Management, 20(1), 19-34.

[7] Puik, E., \& van Moergestel, L. (2010). Agile multi-parallel micro manufacturing using a grid of equiplets. In Precision Assembly Technologies and Systems (pp. 271-282). Springer Berlin Heidelberg.

[8] Zhao, H., Xing, M., Zhao, J., \& Li, H. (2015). Design and Implementation of Multilevel Secure Database Management Access Control. Journal of Applied Science and Engineering Innovation, 2(6), 223-225.

[9] Xingli Jiao, Xiang Gui, Hua Li and Ying Xiong, 2015. Effects of Food Additives on Drying Rate, Rehydration Ratio and Sense Value of Freeze-dried Dumplings. Advance Journal of Food Science and Technology, 8(10): 734-740. 